\title{
Application of Peanut Husk Ash as a Low-Cost Solid Catalyst for Biodiesel Production
}

\author{
Yong-Ming Dai, Kung-Tung Chen, Yu-Jie Wang, and Chiing-Chang Chen
}

\begin{abstract}
This work investigates the use of $\mathrm{Li}_{2} \mathrm{CO}_{3}$-modified waste peanut husk ash as the solid base catalyst for the biodiesel production. The prepared waste peanut husks as the solid base catalyst are characterized by XRD, BET, SEM and TGA for the physical and chemical properties. In the present study, the biodiesel is synthesized from soybean oil through a transesterification reaction catalyzed by the solid base catalyst. Under the optimal reaction conditions of methanol/oil molar ratio $12: 1,5 \%(w t / w t ~ o i l) ~ c a t a l y s t ~ a m o u n t$, and a reaction temperature of $65^{\circ} \mathrm{C}$ for $4 \mathrm{~h}$, there is a $98.4 \%$ conversion to the biodiesel from soybean oil.
\end{abstract}

Index Terms-Biodiesel, transesterification, peanut husks, $\mathrm{Li}_{4} \mathrm{SiO}_{4}$, solid base catalyst, $\mathrm{Li}_{2} \mathrm{CO}_{3}$.

\section{INTRODUCTION}

Under the effects of energy crisis, biomass energy, with the strengths of renewability and low pollution, is considered as a substitute for petroleum to release the energy crisis in a short period of time [1], [2]. Biodiesel, produced by vegetable oil and animal fat through transesterification, is a kind of renewable energy, which presents the characteristics of biodegradability and non-toxicity [3], [4]. Although the transesterification reaction is relatively fast and records high conversions in homogeneous catalyst systems, there are several difficulties in this reaction. The catalyst cannot be recovered and must be neutralized, and they cannot be reused and the separation of fatty acid methyl esters (FAME) from the catalyst during the process also generates large volumes of wastewater. This results in loss of useful material, and produces large quantities of water since the purification of the ester phase is subsequently necessary. The use of heterogeneous solid catalysts could be an attractive solution to overcome these disadvantages. Heterogeneous solid base catalysts have several advantages such as ease of separation of catalysts, recyclability, eco-friendly and environmentally benign [5]. The use of heterogeneous catalysts that rely on the treatment of various catalyst supports, i.e., heterogeneous solid catalysts of $\mathrm{CaO}$ [6], $\mathrm{K}_{2} \mathrm{CO}_{3}$ [7], [8], $\mathrm{SiO}_{2}$ [9], $\mathrm{MgO}$ [10], offers various advantages including the recovery and recycling of the catalyst. Compared with homogeneous base catalysts, heterogeneous catalysts can avoid the

Manuscript received September 5, 2013; revised December 9, 2013. The authors thank NSC Taiwan under the grant of NSC 101-2622-M-142-001-CC1 for financially supporting this study.

Yong-Ming Dai, Yu-Jie Wang, and Chiing-Chang Chen are with the Department of Science Application and Dissemination, National Taichung University of Education, Taichung 40306, Taiwan (e-mail: ccchen@mail.ntcu.edu.tw).

Kung-Tung Chen is with the Department of Chemical and Materials Engineering, Minghsin University of Science and Technology, Hsinchu 30401, Taiwan. saponification of FFAs and are easily separated from product mixtures [11]-[13].

Peanut husks, an agricultural waste available in large quantity, are often burned or discarded directly into farm lands. As a potential adsorbent material, peanut husks can be utilized for such purposes, as they can also bring unlimited number of economic and environmental benefits to industrial wastewater treatment. Thus, they are regarded as an abundant and inexpensive agricultural by-product [14]. Because of the high silica content, waste peanut husks can be an economically viable raw material for producing silicates and silica in recent years [15], [16]. The catalysts remain as a heterogeneous medium. Hence, the purification and washing steps can be eliminated from the process steps. These catalysts appeared to be promising candidates to replace conventional homogeneous catalysts for biodiesel production because the reaction times are low enough to be practical in continuous processes and the preparations are neither difficult nor costly.

Our previous study had applied a $\mathrm{Li}_{2} \mathrm{SiO}_{3}$ on the transesterification. It had been demonstrated that $\mathrm{Li}_{2} \mathrm{SiO}_{3}$ catalyst has a high conversion for the transesterification [17]. This study uses waste peanut husks as a low-cost material to prepare the solid base catalyst using $\mathrm{Li}_{2} \mathrm{CO}_{3}$ as an activating agent through a solid state reaction for the biodiesel production. The prepared solid base catalysts are characterization by XRD FE-SEM, EDX and BET to obtain their physical and chemical properties. In the present study, the objective of this study was to investigate solid catalysts use in biodiesel production, examine the optimum conditions of themethanol/oil ratio, catalyst amounts, reaction time and reaction temperature. These catalysts appeared to be promising candidates to replace conventional homogeneous catalysts for biodiesel production because the reaction times are low enough to be practical in continuous processes and the preparations are neither difficult nor costly.

\section{EXPERIMENTAL}

\section{A. Materials and Preparation of the Catalyst}

Soybean cooking oil (Great Wall Enterprise Co., Taiwan), methanol (ACS grade, ECHO Chemical Co., Miaoli, Taiwan), reagent grade $\mathrm{Li}_{2} \mathrm{CO}_{3}$ (Shimakyu's Pure Chemicals, Osaka, Japan) and $\mathrm{LiOH} \cdot \mathrm{H}_{2} \mathrm{O}$ (Chameleon Reagent, Osaka, Japan) were used as received.

After being thoroughly washed with deionized water, the waste peanut husks were filtered and air-dried at room temperature. A sample of waste peanut husks was converted into peanut husks ash by heating rice husks at $900{ }^{\circ} \mathrm{C}$ for $2 \mathrm{~h}$. The results showed that a highly active solid catalyst could be obtained by mixing and well grinding waste peanut husks 
with $\mathrm{Li}_{2} \mathrm{CO}_{3}$ calcined in air for $4 \mathrm{~h}$.

\section{B. Transesterification Reaction Procedure}

The conversion of soybean oil to biodiesel was performed in a $250 \mathrm{ml}$ flat-bottomed flask, equipped with a reflux condenser and a magnetic stirrer. The reactor was initially filled with $12.5 \mathrm{~g}$ soybean oil, which was heated to $65^{\circ} \mathrm{C}$ for $3 \mathrm{~h}$ while stirring at $300 \mathrm{rpm}$. The reactant was stirred evenly to avoid splashing in the flask at the stirring speed. The timing of the reaction was initiated as soon as the mixture of methanol and the catalyst was added into the reactor. The effects of the molar ratio of methanol to oil $(3: 1-24: 1)$ and catalyst/oil weight ratio (1-7 wt. \%) on the conversion of triglycerides to biodiesel were investigated. All of the experiments were performed at atmospheric pressure. After the transesterification reaction, DI water was added into the reaction mixture to stop the reaction. The biodiesel and glycerol layers were easily separated due to the different densities of 0.86 and $1.126 \mathrm{~g} / \mathrm{cm}^{3}$, respectively. A supernatant was filtered through a common filter paper, and then excess methanol and water were evaporated prior to the fatty acid methyl ester (FAME) analysis.

\section{Instruments and Analytical Methods}

The base strength of the as-prepared catalyst $\left(\mathrm{H}_{-}\right)$was determined using Hammett indicators. Approximately $50 \mathrm{mg}$ of the sample was shaken with $1 \mathrm{ml}$ methanol solution of the Hammett indicator. $2 \mathrm{~h}$ were allowed to elapse for reaching the equilibrium after which no additional color change took place. The basic strength was defined being stronger than the weakest indicator which exhibited a color change, and weaker than the strongest indicator which produced no color change. Bromthymol blue $\left(\mathrm{H}_{-}=7.2\right)$, phenolphthalein $\left(H_{-}=9.8\right), 2$,4-dinitroaniline $\left(H_{-}=15.0\right)$, and 4-nitroaniline $\left(\mathrm{H}_{-}=18.4\right)$, at a concentration of $0.02 \mathrm{~mol} / \mathrm{L}$ were obtained from Sigma-Aldrich (St. Louis, Missouri, USA) and used as Hammett indicators. The characterization of the as-prepared catalysts was performed using a powder X-ray diffractometer (XRD, MAC MXP18, Tokyo, Japan), with $\mathrm{Cu} \mathrm{K \alpha}$ radiation, over a $2 \theta$ range from 20 to $80^{\circ}$, with a step size of $0.04^{\circ}$, and at a scanning speed $3^{\circ} \mathrm{min}-1$. The FAME concentration, expressed as the biodiesel purity of the product, was determined using a gas chromatography system (Thermo trace GC ultra, Thermo Co., Austin, Texas, USA), equipped with a flame ionization detector, a capillary column (Tr-biodiesel (F), Thermo Co., $30 \mathrm{~m}$ in length with $0.25 \mathrm{~mm}$ i.d. and $0.25 \mu \mathrm{m}$ film thickness), the programmed column oven, and a programmed temperature injector. The oven temperature program consisted of starting at $120{ }^{\circ} \mathrm{C}$ (hold 1 min), increasing at a rate of $30{ }^{\circ} \mathrm{C}$ min- 1 to $220{ }^{\circ} \mathrm{C}$ (hold 1 $\mathrm{min}$ ), and then increasing at a rate of $10{ }^{\circ} \mathrm{C}$ min- 1 to $250{ }^{\circ} \mathrm{C}$ (hold $1 \mathrm{~min}$ ). The temperature of the programmed 3 injectors was $90{ }^{\circ} \mathrm{C}$ for $0.05 \mathrm{~min}$, and programmed to $260{ }^{\circ} \mathrm{C}$ at a rate of $10{ }^{\circ} \mathrm{C} \mathrm{min}^{-1}$. Nitrogen was used as a carrier gas with a flow-rate of $2 \mathrm{ml} \mathrm{min-1.} \mathrm{The} \mathrm{amount} \mathrm{of} \mathrm{FAME} \mathrm{was}$ calculated using the internal standard (methyl heptadecanoate) method, according to method EN 14103.

\section{RESULT AND DISCUSSION}

\section{A. Characterizations of As-Prepared Powders}

Fig. 1 shows the XRD results of waste peanut husks(PHA),
$\mathrm{Li}_{2} \mathrm{CO}_{3}$ (JCPDS 87-0728), and the as-prepared catalyst. The parent material, waste peanut husks, is crystalline and consists of $\alpha$-cristobalite (JCPDS 89-3434) and tridymite (JCPDS 73-0469). The crystalline phase of the waste peanut husks is transformed to $\mathrm{Li}_{4} \mathrm{SiO}_{4}$ (JCPDS 74-2145) and a few $\mathrm{Li}_{2} \mathrm{SiO}_{3}$ (JCPDS 37-1472) phase after the solid state synthesis with $\mathrm{Li}_{2} \mathrm{CO}_{3}$. XRD analyses do not show the presence of impurities $\left(\mathrm{Li}_{2} \mathrm{CO}_{3}\right.$ and $\left.\mathrm{SiO}_{2}\right)$, which might form after the experiment from a decomposition reaction of $\mathrm{Li}_{4} \mathrm{SiO}_{4}$ with moisture and $\mathrm{CO}_{2}$ in the air. It can be seen that, the samples showed the diffraction peaks characteristic of the $\mathrm{Li}_{4} \mathrm{SiO}_{4}$. Upon calcination, the as-received PHA and $\mathrm{Li}_{2} \mathrm{CO}_{3}$ underwent decarbonization and dehydration processes that led to the formation of $\mathrm{Li}_{4} \mathrm{SiO}_{4}$. In order to understand the effect of the PHA/ $\mathrm{Li}_{2} \mathrm{CO}_{3}$ mole ratio on the transesterification activity, the catalysts were calcined at PHA/ $\mathrm{Li}_{2} \mathrm{CO}_{3}$ mole ratio. The main crystalline structure of these samples corresponds to the PHA was transformed to the $\mathrm{Li}_{4} \mathrm{SiO}_{4}$ (JCPDS 37-1472) and a few $\mathrm{Li}_{2} \mathrm{SiO}_{3}$ (JCPDS 70-0330) phase after solid state synthesis with $\mathrm{Li}_{2} \mathrm{CO}_{3}$. The different peaks of $\mathrm{Li}_{4} \mathrm{SiO}_{4}$ phase appear at $2 \theta=16.7,17.2$, $22.1,22.5,28.1,29.2,33.7,34.8,38.1$, and the different peaks of $\mathrm{Li}_{2} \mathrm{SiO}_{3}$ phase appear at $2 \theta=18.9,32,33.2,59.1$ when the PHA/ $\mathrm{Li}_{2} \mathrm{CO}_{3}$ mole ratio is $0.5-4$. When the PHA/ $\mathrm{Li}_{2} \mathrm{CO}_{3}$ mole ratio is 0.5 , the diffraction peaks of $\mathrm{Li}_{2} \mathrm{SiO}_{3}$, were observed. With an increase of the PHA/ $\mathrm{Li}_{2} \mathrm{CO}_{3}$ mole ratio, the diffraction peaks of $\mathrm{Li}_{4} \mathrm{SiO}_{4}$ become clear. When PHA/ $\mathrm{Li}_{2} \mathrm{CO}_{3}$ mole ratio increased to 4 , the heights of the diffraction peaks belonging to $\mathrm{Li}_{4} \mathrm{SiO}_{4}$ increased further.

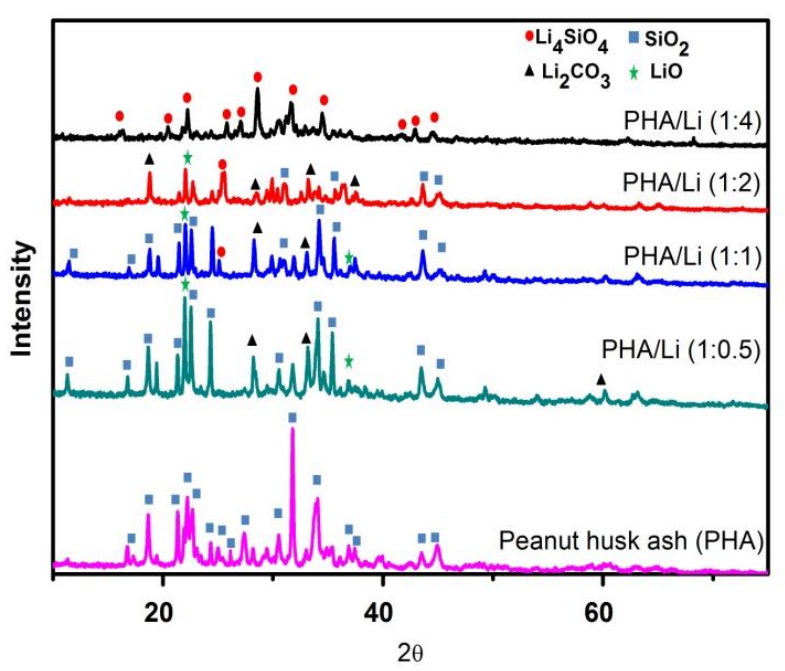

Fig. 1. PHA and as-prepared catalyst by the solid state reaction at $900{ }^{\circ} \mathrm{C}, 4 \mathrm{~h}$; for $\mathrm{Li} / \mathrm{PHA}$ molar ratio = $1 / 0.5,1 / 1,1 / 2$ and $1 / 4$.

Fig. 2a presents FE-SEM images of the PHA sample and the chemical composition of the ash determined by EDS. The FE-SEM micrograph of the PHA indicates that the surface is spherical and impermeable porous in nature. Elemental composition with EDS shows that $\mathrm{SiO}_{2}$ is the mainly detected component, with a relatively low $\mathrm{K}$ and $\mathrm{Ca}$ content (Fig. 2b). The PHA exhibited the type III nitrogen adsorptiondesorption isotherm (Fig. 2c). The type III isotherm of PHA generally shows prominent adsorption at high relative pressures $\left(\mathrm{P} / \mathrm{P}_{0}\right)$, indicating macropore adsorption. The corresponding BET specific surface area was calculated to be $1.21 \mathrm{~m}^{2} / \mathrm{g}$. The pore size distribution calculated from the $\mathrm{BJH}$ 
method showed a broad pore size ranging from 900-1000 nm (Fig. 2d).
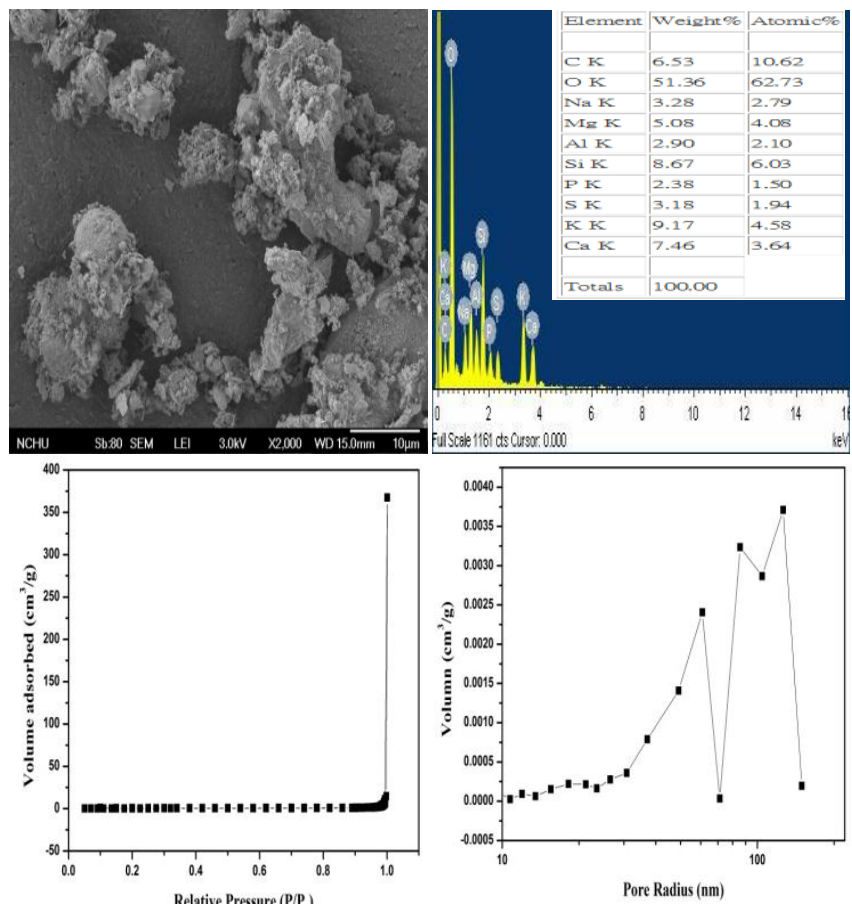

Fig. 2. Characterization of the synthesized LPMSN. (a)FESEM and (b) EDX (c) Nitrogen adsorption-desorption isotherm and (d) pore size distribution.

FE-SEM images shows the as prepared catalyst by the solid state reaction at $900{ }^{\circ} \mathrm{C}, 4 \mathrm{~h}$, for $\mathrm{PHA} / \mathrm{Li}$ molar ratio $1 / 0.5,1 / 1,1 / 2$ and $1 / 4$. The surface morphology of the catalyst is examined by FE-SEM (Fig. 3). For the sample with Li/PHA (1/0.5) obtained at $900{ }^{\circ} \mathrm{C}$ (Fig. 3a), a lot of amorphous silica still exist and keep their initial microstructure. Some homogeneous spherical crystals have very smooth surface with a mean diameter of $50 \mu \mathrm{m}$. Fig. $3 \mathrm{~b}$ shows the irregular-shaped particles of the Li/PHA morphology ranged between 10 and $20 \mu \mathrm{m}$. The sample shows non-homogeneous polyhedral agglomerates; and, the particles and amorphous silica disappear. When the molar ratio is up to (1/2), (see Fig. 3c), the homogeneous and coralloid crystal is observed. It shows that the catalyst synthesized is composed of nano-sized particles, which are about $10 \mu \mathrm{m}$ in size, and that each particle is nearly coralloid crystal in shape and dense in density. While at molar ratio (1/4), see in Fig. 3d, the particles show the obvious agglomeration. When the $\mathrm{Li} / \mathrm{Si}$ molar ratio is up to (1/4), the particles show nonhomogeneous polyhedral crystals with the side length of about $20 \mu \mathrm{m}$.

\section{B. Transesterification Reaction Condition Optimization}

To make direct comparisons, the same reaction conditions, as shown in Table I, are employed to each catalyst in all experiments. The reaction conditions are not optimized for the highest reaction yield; however, they provide a way to compare the activities of the catalysts. Obviously, it is observed from Table I that the PHA exhibits no activity. However, when $\mathrm{Li}_{2} \mathrm{CO}_{3}$ is modified PHA, the catalysts show catalytic activities. Thus, it is essential to modify PHA from $\mathrm{Li}_{2} \mathrm{CO}_{3}$ to generate the catalytic activities for the transesterification reaction. It can be concluded that the observed activities of the $\mathrm{Li}_{2} \mathrm{CO}_{3}$-modified PHA catalysts seem to be related to their base strengths and basicity values, i.e. the higher base strengths and basicity values of the catalysts result in the higher conversions.
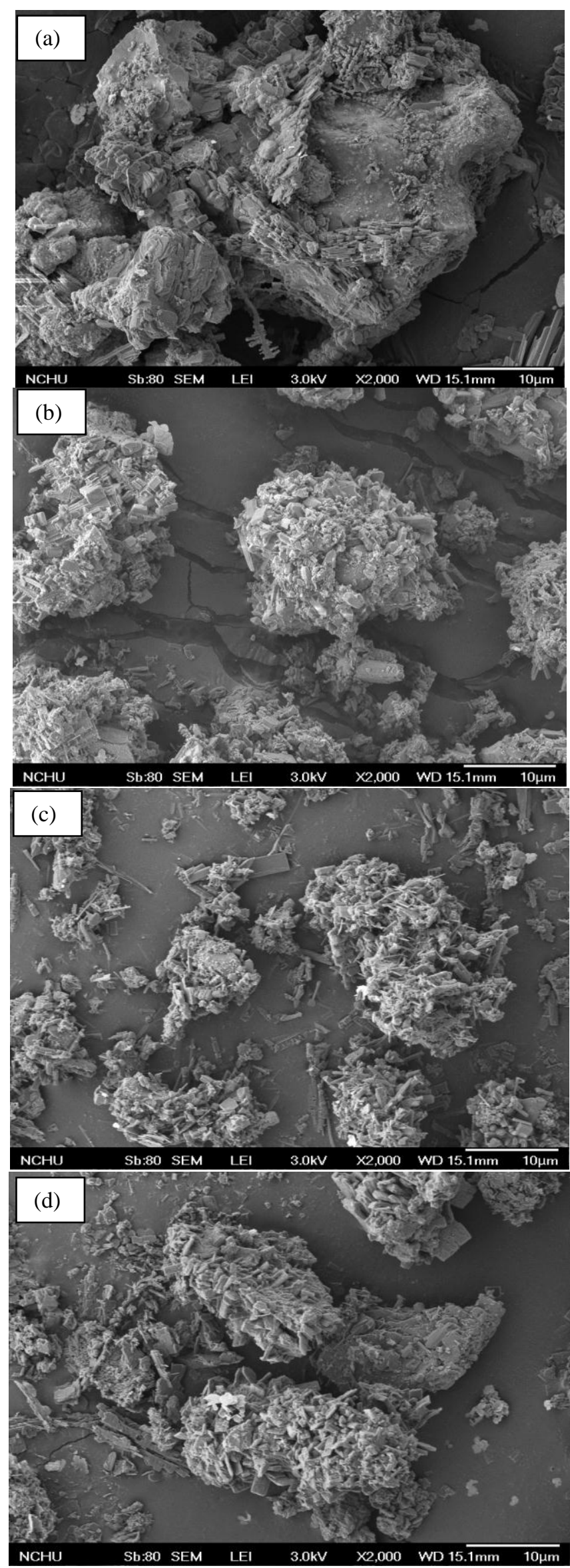

Fig. 3. FE-SEM images of as prepared catalyst by the solid state reaction a $900{ }^{\circ} \mathrm{C}, 4 \mathrm{~h}$, for $\mathrm{Li} / \mathrm{PHA}$ molar ratio (a) $1 / 0.5$ (b) $1 / 1$ (c) $1 / 2$ (d) $1 / 4$ 
TABLE I: THE ARRANGEMENT OF CHANNELS

\begin{tabular}{cccc}
\hline \hline Catalyst & Li/PHA molar ratio & Basic strength & *Conversion $(\%)$ \\
\hline PHA & 0 & $H_{-}<7.2$ & 0.36 \\
Li/PHA & $1 / 0.5$ & $7.2<H_{-}<9.8$ & 65.8 \\
Li/PHA & $1 / 1$ & $9.8<H_{-}<15.0$ & 88.5 \\
Li/PHA & $1 / 2$ & $9.8<H_{-}<15.0$ & 89.5 \\
Li/PHA & $1 / 4$ & $9.8<H_{-}<15.0$ & 77.9 \\
\hline *Reaction conditions: 12.5 g soybean oil; methanol/oil molar ratio, $12: 1 ;$ \\
catalyst amount, 1wt\%; reaction time, 3 h; methanol reflux temperature \\
and conventional heating method .
\end{tabular}

Fig. 4 shows different calcination temperature of the Li/PHA (1/4) through the transesterification process. With the calcination temperature at $900^{\circ} \mathrm{C}$, the conversion achieves $46.3 \%$, while the conversion achieves $93 \%$ when the temperature is higher than $600^{\circ} \mathrm{C}$, and the higher conversion $88.9 \%$ appears on the calcination temperature at $900^{\circ} \mathrm{C}$. However, the transfer rate decreases at the calcination temperature $1000^{\circ} \mathrm{C}$. It might be resulted from the poison process by some unknown reaction with catalysts, indicating that high calcination temperature should be avoided.

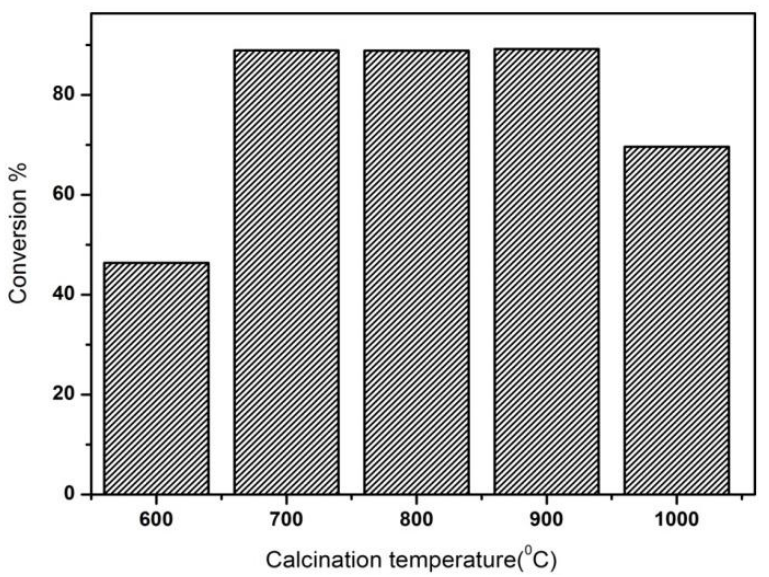

Fig. 4. Influence of calcination temperature on the conversion. (12.5 g soybean oil; methanol/oil molar ratio, 12:1; catalyst amount, $1 \mathrm{wt} \%$; reaction time, $3 \mathrm{~h}$; methanol reflux temperature and conventional heating method).

The stoichiometric molar ratio of alcohol to oil for transesterification is $3: 1$; however, the alcohol to oil molar ratio should be higher than that of the stoichiometric molar ratio in order to drive the reaction towards completion and shift it to the right hand side to produce more FAME [18]. In Fig. 5, the result suggests that the rate of FAME formation is lower at lower molar ratios of methanol and increases when the molar ratio reaches the maximum value of 12 . The increase in conversion is due to the shift in equilibrium towards the formation of FAME. These results indicate that the maximum conversion is $97.15 \%$ for the Li/PHA (1/4) catalysts. Further increasing the alcohol to oil ratio leads to decrease the oil concentration and accordingly decrease the reaction rate. Therefore, 12:1 is the appropriate methanol/oil molar ratio for this reaction. The excess methanol can be collected and recycled. Catalyst amount is an important parameter which affects the conversion of triglycerides to methyl esters. As shown in Fig. 5, the conversion reaches a plateau value at the catalyst weight percentage between 2 and $6 \mathrm{wt} \%$. Additional catalysts increase the contact opportunity of the catalyst and the reactant, which directly influence the reaction speed and the conversion. In general, increasing catalyst amount will increase the number of active sites available for the adsorption of the reactants, resulting in a more rapid increase in the number of sites of interaction between the reactants. However, with a further increase in the loading amount, the conversion has no significant difference. The rational reason is due to the rise of mixing problem (oil/MeOH/catalyst) and the resistance of mass transfer [19]. Under present reaction conditions, the optimal catalyst amount is $5 \mathrm{wt} \%$.

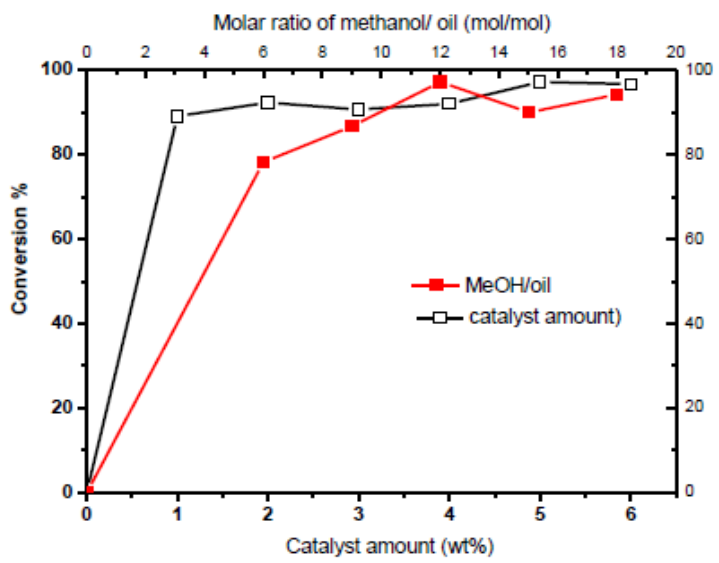

Fig. 5. Influence of catalyst amount and methanol/oil molar ratio on the conversion. (12.5 g soybean oil; reaction time, $3 \mathrm{~h}$; methanol reflux temperature and conventional heating method).

Reaction time is an important factor in the whole process. Fig. 6 shows that the transfer rate increases with time and has a maximum value at 4 hour. Four different temperatures are used for the transesterification of refined soybean oil with methanol (12:1) using $5 \mathrm{wt} \%$ catalyst. After $3 \mathrm{~h}$, conversions are $97.15,35.65,24.33,43.5$ and $21.59 \%$ for $65,55,45,35$ and $25{ }^{\circ} \mathrm{C}$, respectively. The temperature clearly influences the reaction rate and the biodiesel purity. Glycerol on the surface of catalysts may cause catalysts loss activity. $\mathrm{CaO}$ has higher trasnesterification activity among all Alkali and alkaline earth oxides, it would react with glycerol produced from transesterification process to form Ca-glyceroxides [20]. It might be resulted from the poison process by Ca-glyceroxides is decrease reutilization. Another key aspect in the development of new solid catalysts for biodiesel production, under heterogeneous conditions, is the possibility of reutilization of the solid catalyst.

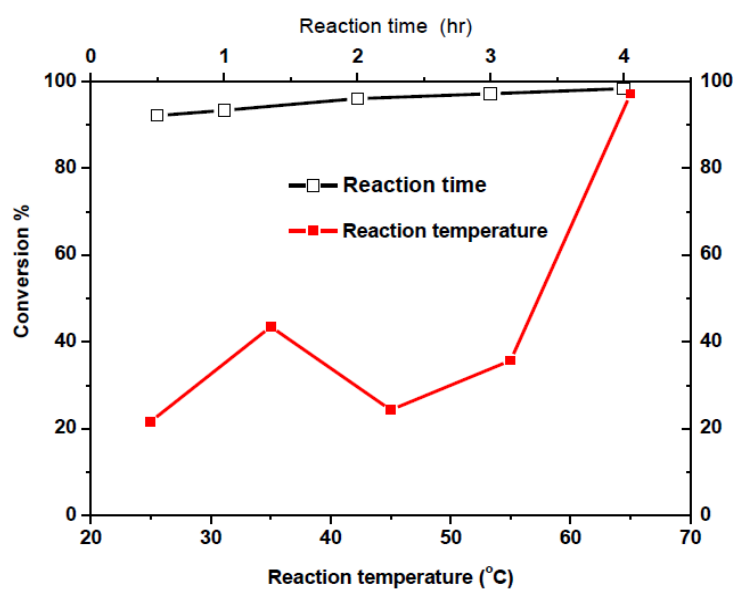

Fig. 5. T Influence of reaction time and reaction temperature on the conversion. (12.5 g soybean oil; methanol/oil molar ratio, 12:1; catalyst amount, 5wt\%; methanol reflux temperature and conventional heating method). 
Fig. 7 shows that Li2CO3-modified PHA (1/4) catalyst exhibits a fairly good operational stability, i.e., $96.84 \%$ of the conversion for the first reaction and $84.5 \%$ of the conversion retained for the fifth reaction. It clearly indicates the advantage of solid base catalyst for the reaction stability and the possible feasibility can be enhanced in industrial production.

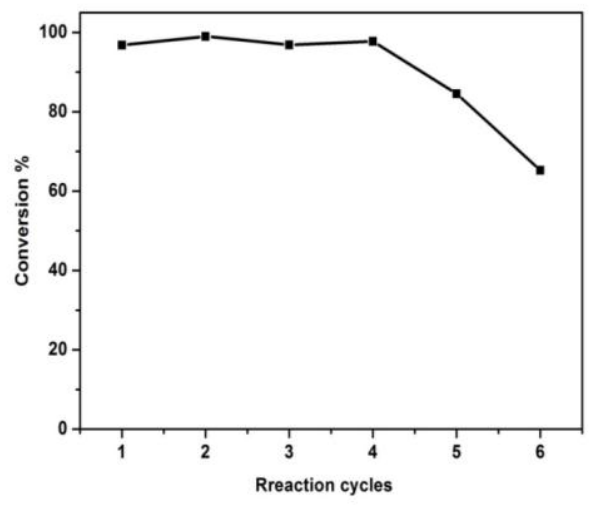

Fig. 7. Reusability study after five reaction cycles for catalyst $(12.5 \mathrm{~g}$ soybean oil; methanol/oil molar ratio, $12: 1$; catalyst amount, $5 \mathrm{wt} \%$; reaction time, $3 \mathrm{~h}$; methanol reflux temperature and conventional heating method).

\section{CONCLUSION}

$\mathrm{Li}_{2} \mathrm{CO}_{3}$-modified waste peanut husks as the solid base catalyst are easy to synthesize using a solid-state reaction and can directly be used for the biodiesel production without further catalyst synthesis processes, involving either drying or thermal treatment. The waste peanut husks as the solid base catalyst demonstrate excellent catalytic activities and stable catalytic activities of transesterification reactions. Developing waste peanut husks as the solid base catalyst for biofuel production would become a new and promising way in the future.

\section{ACKNOWLEDGMENT}

The authors thank NSC Taiwan under the grant of NSC 101-2622-M-142-001-CC1 for financially supporting this study.

\section{REFERENCES}

[1] N. Viriya-Empikul, P. Krasae, B. Puttasawat, B. Yoosuk, N. Chollacoop, and K. Faungnawakij, "Waste shells of mollusk and egg as biodiesel production catalysts," Bioresource Technology, vol. 101, pp. 3765-7, 2010

[2] G. W. Huber, S. Iborra, and A. Corma, "Synthesis of transportation fuels from biomass: Chemistry," Catalysts, and Engineering. Chemical Reviews, vol. 9, pp. 4044-98, 2006.

[3] E. G. Shay, "Diesel fuel from vegetable oils: Status and opportunities," Biomass and Bioenergy, vol. 4, pp. 227-242, 1993.

[4] S. Saka and D. Kusdiana, "Biodiesel fuel from rapeseed oil as prepared in supercritical methanol," Fuel, vol. 80, pp. 25-231, 2001.

[5] D. G. B. Boocock, S. K. Konar, V. Mao, and H. Sidi, "Fast one-phase oil-rich processes for the preparation of vegetable oil methyl esters," Biomass and Bioenergy, vol. 11, pp. 43-50, 1996.

[6] H. Sun, J. Z. Duan, P. Chen, H. Lou, and X. M. Zheng, "Room temperature transesterification of soybean oil to biodiesel catalyzed by rod-like $\mathrm{Ca}_{\mathrm{x}} \mathrm{SiO}_{\mathrm{x}+2}$ solid base," Catalysis Communications, vol. 12, pp. 1005-1008, 2011

[7] X. J. Liu, H. Y. He, Y. J. Wang, S. L. Zhu, and X. L. Piao, "Transesterification of soybean oil to biodiesel using $\mathrm{CaO}$ as a solid base catalyst," Fuel, vol. 87, pp. 216-221, 2008.
[8] J. X. Wang, K. T. Chen, S. T. Huang, and C. C. Chen, "Biodiesel production from soybean oil catalyzed by $\mathrm{K}_{2} \mathrm{SiO}_{3} / \mathrm{C}$," Chinese Journal of Catalysis, vol. 32, pp. 1592-1596, 2011.

[9] H. Liu, L. G Su, F. F. Liu, and C. Li, "Cinder supported $\mathrm{K}_{2} \mathrm{CO}_{3}$ as catalyst for biodiesel production," Applied Catalysis B: Environmental, vol. 106, pp. 550-558, 2011.

[10] L. L. Mguni, M. Mukenga, K. Jalama, and R. Meijboom, "Three-dimensional ordered mesoporous Co-Mn oxide: A highly active catalyst for "storage-oxidation" cycling for the removal of formaldehyde," Catalysis Communications, vol. 34, pp. 52-57, 2013.

[11] Y. Wang, P. L. S. Ou, and Z. Zhang, "Preparation of biodiesel from waste cooking oil via two-step catalyzed process," Energy Conversion and Management, vol. 48, pp.184-188, 2007.

[12] A. Casas, C. M. Fernández, M. J. Ramos, Á. Pérez, and J. F. Rodríguez, "Optimization of the reaction parameters for fast pseudo single-phase transesterification of sunflower oil," Fuel, vol. 89, pp. 650-658, 2010.

[13] D. Kusdiana and S. Saka, "Effects of water on biodiesel fue production by supercritical methanol treatment," Bioresource Technology, vol. 91, pp. 289-295, 2004.

[14] Z. H. Hu, N. X. Wang, J. Tan, J. Q. Chen, and W. Y. Zhong, "Kinetic and equilibrium of cefradine adsorption onto peanut husk," Desalination and Water Treatment, vol. 37, pp. 160-168, 2012.

[15] I. Safarika and B. M. Safarikova, "Magnetic fluid modified peanut husks as an adsorbent for organic dyes removal," Physics Procedia, vol. 9, pp. 274-278, 2010.

[16] H. D. Ozsoy, H. Kumbur, and Z. Ozer, "Adsorption of copper (II) ions to peanut hulls and Pinus brutia sawdust," International Journal of Environment and Pollution, vol. 31, pp. 125-134, 2007.

[17] J. X. Wang, K. T. Chen, S. T. Huang, J. S. Wu, P. H. Wang, and C. C. Chen, "Production of biodiesel through transesterification of soybean oil using lithium orthosilicate solid catalyst," Fuel Processing Technology, vol. 104, pp. 167-173, 2012.

[18] S. H. Wang, Y. B. Wang, and J. M. Jehng, "Preparation and characterization of hydrotalcite-like compounds containing transition metal as a solid base catalyst for the transesterification," Applied Catalysis A: General, vol. 135, pp. 439-440, 2012.

[19] X. Y. Liao, Y. L. Zhu, S. G. Wang, and Y. W. Li, "Producing triacetylglycerol with glycerol by two steps: Esterification and acetylation," Fuel Processing Technology, vol. 90, pp. 988-993, 2007.

[20] N. Pasupulety, K. Gunda, Y. Q Liu, G. L. Rempel, and F. T. T. Ng, "Production of biodiesel from soybean oil on $\mathrm{CaO} / \mathrm{Al} 2 \mathrm{O} 3$ solid base catalysts," Applied Catalysis A, General, vol. 452, pp. 189-202, 2013.

Yong-Ming Dai completed his $\mathrm{PhD}$ at the National Chung Hsing University (Taiwan) in 2010. He joined the group of Chiing-Chang Chen at National Taichung University of Education in 2011 as a postdoctoral fellow. His scientific interests are in the technological applications of material science, heterogeneous catalysis and energy fuel.

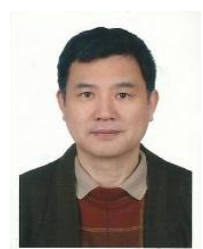

Kung-Tung Chen is a professor of Minghsin University of Science and Technology, Hsinchu, in Taiwan. He received his Ph.D. (1993) from the National Tsing Hua University (Taiwan). His research interests include sustainable and green chemistry, environmental remediation, and Environmental impact assessment.

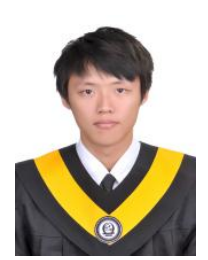

Yu-Jie Wang is a graduate student of National Taichung University of Education, Taichung, in Taiwan. He joined the group of Chiing-Chang Chen in 2010 as a graduate student. His scientific interests are in the technological applications of heterogeneous.

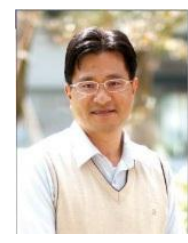

Chiing-Chang Chen is a professor of National Taichung University of Education, Taichung, in Taiwan. He received his Ph.D. (1994) from the National Tsing Hua University (Taiwan). His main research interests: applied heterogeneous catalysis and photocatalysis to the solution of environmental problems, sustainable and green chemistry and environmental remediation. 